\title{
Cyclooxygenase Inhibition in Cancer Immunotherapy: Combination of Indomethacin with Cancer Vaccines Is Not Always Beneficial
}

\author{
Giselle Hevia ${ }^{*}$, Isabel Pablos ${ }^{2}$, Marilyn Clavell1', Judith Raymond1, Mayrel Labrada1, \\ Luis E. Fernández ${ }^{1}$ \\ ${ }^{1}$ Immunobiology Division, Center of Molecular Immunology (CIM), Havana, Cuba \\ ${ }^{2}$ Deparment of Molecular Biology, University of Salzburg, Salzburg, Austria \\ Email: ${ }^{\star}$ giselleh@cim.sld.cu
}

How to cite this paper: Hevia, G., Pablos, I., Clavell, M., Raymond, J., Labrada, M. and Fernández, L.E. (2017) Cyclooxygenase Inhibition in Cancer Immunotherapy: Combination of Indomethacin with Cancer Vaccines Is Not Always Beneficial. Journal of Cancer Therapy, 8, 188-209.

https://doi.org/10.4236/jct.2017.82016

Received: October 8, 2016

Accepted: February 13, 2017

Published: February 16, 2017

Copyright ( 2017 by authors and Scientific Research Publishing Inc. This work is licensed under the Creative Commons Attribution International License (CC BY 4.0).

http://creativecommons.org/licenses/by/4.0/

\begin{abstract}
Cyclooxygenase (COX)-1, but preferable COX-2 catalyzes the synthesis of PGE2 in several tumors, promoting angiogenesis and a suppressive inflammation in their microenvironments. Different types of cancer vaccines have been combined with COX-2 inhibitors, assuming that its particular mechanism of action will not influence the overall results of the combination. In this research, a possible relationship between the type of cancer vaccine and the outcome of the combination with a COX inhibitor was experimentally addressed. We investigated whether nonsteroidal anti-inflammatory drugs (NSAIDs) affect the immune response to vaccination. Three adjuvants were evaluated for humoral and cellular response using ovalbumin (OVA) as antigen. We evaluated also the impact of indomethacin in five tumor models and the correlation of this effect with the secretion of prostaglandin E2 (PGE2) of these cells. We finally studied the combination of indomethacin with two cancer vaccines in three different experimental settings. COX inhibitor did not interfere with dendritic cells maturation in vitro and did not affect the frequency of splenic immune cell populations in mice. However, the induction of OVA-specific antibodies is affected by the COX inhibitor but its impact on cytotoxic CD8+ T cell response is adjuvant-dependent. In contrast, the antitumor effect of the COX inhibitor in the 3LL-D122 tumor model is not mediated by CD4+ or CD8+ T cells. Interestingly, the in vivo effect observed in this model and others didn't correlate with levels of PGE2 secretion by the tumor cell lines in vitro. Finally, the combination of a COX inhibitor with cancer vaccines may depend on the type of the cancer vaccine.
\end{abstract}

\section{Keywords}

Cyclooxygenase Inhibitors, Cancer Vaccines, Combination Therapy 


\section{Introduction}

Over the last few decades, several studies have been focused on the search of strategies to enhance effective antitumor immune responses. Among these strategies, tumor vaccination is a promising approach for cancer treatment due to the specificity of response, low toxicity, and induction of long-term memory [1] [2]. However, despite all of the noticeable progress made so far, there remain concerns about the limited clinical efficacy of this powerful therapeutic modality. Up until now, a number of immunosuppressive factors, including immune regulatory pathways/cells and tumor derived factors, have been identified which can impair an effective antitumor immunotherapeutic response [3]. The development of strategies to break these immunosuppressive mechanisms responsible for tumor immune escape is a key goal for an effective anticancer immunotherapy [4]. In this respect, nonsteroidal anti-inflammatory drugs (NSAIDs) exhibit a great potential to enhance the effectiveness of cancer immunotherapy [3].

The main therapeutic target of NSAIDs is the enzyme cyclooxygenase (COX) [5]. The COX-1 isoform is implicated in homeostasis while the COX-2 is implicated in inflammatory process and in promoting tumorigenesis [6] [7] [8]. Several preclinical and clinical trials have demonstrated an impact of NSAIDs, especially the selective COX-2 inhibitors, either alone or in combination with other therapies, in reducing cancer risk, as well as improving survival rate in different types of cancer [9] [10] [11]. Even when the underlying mechanisms of these chemopreventive effects have not yet fully elucidated, some studies indicate that the selective COX-2 inhibitors, can increase the tumor site infiltration of CD4+ and $\mathrm{CD} 8+\mathrm{T}$ cells, thereby positively regulating the tumor specific host immune response [12]-[17]. On the other hand, these drugs can modulate the activity of regulatory cells as tumor associated macrophages, $\mathrm{T}$ regulatory cells and myeloid-derived suppressor cells through the inhibition of prostaglandin E2 (PGE2), a key mediator of the immunosuppressive role of this kind of cells [18] [19] [20] [21]. These accumulating evidences support the idea that NSAIDs modulate the effector mechanisms of anti-tumor immunity through COX-2 dependent ways. Such actions may constitute an important facet of the effectiveness of anti-cancer immunotherapy [22]. However, in the last few years, many studies have showed promising results of the non-selective COX inhibitors in the treatment of cancer. The underlying mechanisms of this effect implicate both COX-1-dependent and COX-independent ways [23] [24] [25] [26] [27]. However, even for the promising results of this non-selective inhibitor in the cancer therapy, there just a few studies concerning the combination of these NSAIDs with cancer vaccine as well as its impact on the immune response to vaccination.

On the other hand, some cancer vaccines using very small size proteoliposomes (VSSP) as adjuvant are currently under investigation [28] [29] [30] [31]. This adjuvant has been proved to promote dendritic cell (DC) maturation, antigen cross presentation to CD8+ T cells, $\mathrm{T}$ helper (Th) polarization, enhance cytotoxic T lymphocyte (CTL) response [32] [33] and induce a repopulation of immune cells in leukopenic scenarios [34] while simultaneously abrogating the 
immunosuppressive capacity of myeloid-derived suppressor cells [35].

Considering this, here, we evaluated the effect of the non-selective inhibitor indomethacin on some immune cells and its impact in the humoral and cellular response to vaccination. We studied also the effect of this NSAID in different tumor models either alone or in combination with different cancer vaccines.

\section{Materials and Methods}

\subsection{Mice}

C57BL/6 and Balb/c female mice, 8- to 12-week-old, purchased from the Center for Laboratory Animal Production (CENPALAB), were treated according to the Cuban National Laboratory Animal Use Guidelines. All animals were maintained under specific-pathogen-free conditions at the CIM, (Havana, Cuba).

\subsection{Cell Lines and Culture Conditions}

MB16-F10 (melanoma), TC1 (lung epithelial cell line expressing HPV-16 E6 and E7, and an activated ras oncogene) and 3LL-D122 (Lewis lung carcinoma) are murine cell lines derived from C57BL/6. 4T1 (mouse mammary carcinoma) and CT26 (carcinogen-induced, undifferentiated colon carcinoma) are cell lines derived from Balb/c mice. All cell lines were grown in DMEM-F12 (Gibco) supplemented with $10 \%$ fetal calf serum (FCS) (Hyclone), $2 \mathrm{mM}$ L-glutamine, 1 $\mathrm{mM}$ sodium pyruvate, penicillin $100 \mathrm{U} / \mathrm{mL}$, and streptomycin $100 \mu \mathrm{g} / \mathrm{mL}$ (Life Technologies).

\subsection{COX Inhibition}

COX inhibition was achieved using indomethacin. For in vitro experiments, a $0.15 \mathrm{M}$ stock solution of indomethacin (Sigma) was prepared in $1 \mathrm{M}$ Tris- $\mathrm{HCl}$, $\mathrm{pH} 8.2$, and then diluted with culture medium at the different concentrations evaluated. For in vivo experiments, a stock solution of indomethacin (Quimefa) was prepared in ethanol $20 \%$ at a final concentration of $2.5 \mathrm{mg} / \mathrm{mL}$. This was further added to the drinking bottles at different concentrations. In all the experiments, fresh drinking water was prepared three times a week.

\subsection{Effect of COX Inhibition on Bone Marrow-Derived Dendritic Cells in Vitro}

Bone marrow cells were harvested from femurs and tibias and cultured in the presence of Flt-3 ligand at 15\% in IMDM medium (Gibco) as described elsewhere [36] [37] Twenty-four hours before harvesting, DC were matured with 1 $\mu \mathrm{g} / \mathrm{ml}$ LPS (Sigma) with or without indomethacin at $0.5 \mu \mathrm{M}$ or $10 \mu \mathrm{M}$. Expression of cell surface markers was analyzed using a Gallios flow cytometer. The following goat anti-mouse conjugated antibodies specific for surface markers were used (PE: phycoerythrin; FITC: fluorescein isothiocyanate): anti-CD11cPE (eBioscience 12-0116-42), anti-CD40-FITC (BD Pharmingen, 553790), anti-CD80-FITC (BD Pharmingen, 553768) and anti-I-Ad-FITC (eBioscience 11-535185). 


\subsection{Effect of COX Inhibition on Tumor Growth in Different Tumor Models}

C57BL/6 mice were challenged with 3LL-D122 clone $\left(2 \times 10^{5}\right.$ cells $)$ into the right hind footpad and were weighed once a week. The depletion study in this model was done by intraperitoneal injection with $1 \mathrm{mg}$ of anti-CD4 or anti-CD8 monoclonal antibodies. 3LL-D122 tumor volume was calculated by the formula $\pi / 6$ $\times \mathrm{a}^{2}$, where $\mathrm{a}$ is the diameter of the tumor. Indomethacin was prepared from the stock solution at three different final concentrations, 10, 20 and $40 \mu \mathrm{g} / \mathrm{mL}$, equivalent to 25,50 and $100 \mu \mathrm{g} / \mathrm{mouse} /$ day.

MB16-F10 $\left(10^{3}\right.$ cells $)$ or TC1 $\left(10^{6}\right.$ cells $)$ tumor cell lines were inoculated in C57BL/6 mice and 4T1 ( $10^{4}$ cells) or CT26 ( $10^{5}$ cells) were inoculated in Balb/c mice. In all cases the inoculations were made subcutaneously and tumor volume was calculated by the formula $\pi / 6 \times a \times b^{2}$, where $b$ is the smaller dimension of the tumor. Indomethacin was prepared from the stock solution at a final concentration of $20 \mu \mathrm{g} / \mathrm{mL}$ ( $50 \mu \mathrm{g} / \mathrm{mouse} /$ day). In all tumor models, the treatment with indomethacin started at day 0 and was maintained until the end of the experiment.

\subsection{Determination of Prostaglandin E2 Concentration}

Prostaglandin E2 (PGE2) concentration was determined by ELISA, using a Prostaglandin E2 Parameter Assay Kit (R \& D Systems SKE004B). Cell lines were culture for $24 \mathrm{~h}$ and then the supernatant were collected. PGE2 levels were expressed as $\mathrm{ng} / \mathrm{ml} / 1 \times 10^{6}$ cells.

\subsection{Effect of COX Inhibition on Immune Cell Populations}

Healthy C57BL/6 and Balb/c were treated or not with indomethacin for 14 days. On days 0,7 and 14 spleens were removed and the isolated splenocytes were incubated with specific monoclonal antibodies for B cells, CD4+ T and CD8+ T cells for $30 \mathrm{~min}$ at $4^{\circ} \mathrm{C}$. Cells were analyzed using a Gallios flow cytometer. The following monoclonal antibodies were used: anti-CD3-FITC (BD Pharmingen, 555274), anti-CD4-PE (eBiocience 12-0041-83), anti-CD8-PE (eBiocience 12-0081-83), anti-B220-PE (BD Pharmingen 553090) and anti-I-Ad-FITC.

\subsection{Measurement of Antibodies to OVA}

$\mathrm{Balb} / \mathrm{c}$ mice were vaccinated by SC route with $50 \mu \mathrm{g}$ of OVA with $60 \mu \mathrm{L}$ of CFA or $50 \mu \mathrm{g}$ of OVA with $250 \mu \mathrm{g}$ of Alum on days 0,14 and 28 to induce a Th1 or Th2 immune response. Sera were obtained on days 21, 35 and 42. Indomethacin was given during all experiment. Anti-OVA total IgG, IgG1, IgG2a and IgG2b antibodies were measured using an ELISA. In brief, 96-well flat-bottom microtiter plates were incubated with $10 \mu \mathrm{g} / \mathrm{mL}$ of OVA at $4^{\circ} \mathrm{C}$ overnight. The plates were washed with PBS-Tween $20(0.05 \%)$ and then blocked with PBS-skim milk powder $(1 \%)$ for $1 \mathrm{~h}$ at $37^{\circ} \mathrm{C}$. After washing, the plates were incubated with 100 $\mu \mathrm{L}$ of each serum sample, dilute 1:1000 for IgG and IgG1 measurement or 1:100 for IgG2a and IgG2b measurement, for $1 \mathrm{~h} 37^{\circ} \mathrm{C}$. After washing, $100 \mu \mathrm{L} /$ well of 
isotype-specific antibodies were added and incubated for $1 \mathrm{~h}$ at $37^{\circ} \mathrm{C}$. The following antibodies were used: alkaline phosphatase-labeled anti mouse IgG (whole molecule) (Sigma) dilute 1:5000, HRP-labeled anti mouse IgG1 (Pharmingen) dilute 1:1000 and biotin anti mouse IgG2a or IgG2b (Pharmingen) dilute 1:5000. After washing, streptavidin-alkaline phosphatase diluted 1:5000 was added for detection of IgG2a/IgG2b and incubated $1 \mathrm{~h}$ at $37^{\circ} \mathrm{C}$. The plates were then washed with PBS-Tween 20 and $100 \mu \mathrm{L}$ of p-nitrophenylphosphate $1 \mathrm{mg} /$ $\mathrm{mL}$ (Richmond) was added per well for detection of IgG, IgG2a and IgG2b. The absorbance was then measured at $405 \mathrm{~nm}$. For the detection of IgG1, o-phenylenediamine substrate (Sigma Chemical Co.) was added, and absorption at 492 nm was read.

\subsection{In Vivo Cytotoxic T Lymphocyte (CTL) Assay}

To evaluate the antigen-specific cytotoxic T lymphocyte (CTL) response in the presence of indomethacin, C57BL/6 mice were vaccinated subcutaneously with 1 mg of OVA with VSSP or Poly I:C as adjuvants. VSSP was given at $200 \mu \mathrm{g}$ protein per mouse and Poly I:C was given at $100 \mu \mathrm{g}$ per mouse. All groups received three doses of each vaccine or PBS, on days 0,1 and 7 for the OVA/VSSP mixture and on days 0,1 and 2 for the OVA/ Poly I:C.

The cytolytic activity was assayed 9 after the first vaccination. Splenocytes from naive mice were differentially labeled $\left(5 \mathrm{~min}\right.$ at $\left.37^{\circ} \mathrm{C}\right)$ with carboxyfluorescein diacetate succinimidyl ester (CFSE, Molecular Probes). CFSE high (2 $\mu \mathrm{M})$ cells pulsed with SIINFEKL peptide $\left(1 \mu \mathrm{M} ; 60 \mathrm{~min}\right.$ at $37^{\circ} \mathrm{C}, 5 \% \mathrm{CO}_{2}$, followed by extensive washing to remove free peptide) were used as targets, whereas CFSE low $(0.2 \mu \mathrm{M})$ cells served as control. Target and control cells were co-injected intravenously in a 1:1 ratio to vaccinated mice. Twenty-four hours later, inguinal lymph nodes were harvested and both fluorescent intensities (CFSE high and CFSE low) were determined by FACS. The percentage of specific lysis was calculated as: $100-[($ CFSE high/CFSE low $) \times 100]$.

\subsection{Evaluation of the Combination of Cancer Vaccines with COX Inhibition}

TC1 model. TC1 cells were injected subcutaneously in the right flank at $10^{6}$ cells per mouse. When tumor became visible, mice were vaccinated with a formulation containing $50 \mu \mathrm{g}$ of E7 peptide (RAHYNIVTF) with $160 \mu \mathrm{g}$ of VSSP. The total injected volume was $200 \mu \mathrm{l} /$ mouse. All immunizations were given subcutaneously twice at 2 -week intervals. The treatment with indomethacin started with the first immunization.

3LL-D122 model. NGcGM3/VSSP vaccine was prepared as described by Estevez [38]. C57BL/6 mice challenged with 3LL-D122 clone $\left(2 \times 10^{5} /\right.$ mouse $)$ into the right hind footpad, SC were treated twice with NGcGM3/VSSP $(200 \mu \mathrm{g}$ per mouse), 7 and 21 days after tumor implantation, as described previously [39]. Primary tumors were surgically removed and 21 days after, animals were sacrificed. The spontaneous lung metastases were quantified by weighing the lungs. 
Control groups received PBS. Indomethacin was given to the mice since the beginning of the experiment until the surgery. One week later, indomethacin was given again.

\subsection{Statistical Analyses}

Mann Whitney $U$ test for paired comparison of values or an ANOVA combined with a Multiple Comparisons Test were used. For the frequency analysis was use a Chi-square test. Differences were considered significant if $p<0.05$. The Pearson $r$ coefficients and $p$ values were calculated using GraphPad Prism 5 software.

\section{Results}

\subsection{COX Inhibitor Indomethacin, Does Not Affect DC Maturation in Vitro}

DC expresses relevant surface molecules such as CD11c, CD40, CD80 and MHC class II, with crucial functions for these professional antigen-presenting cells. To evaluate whether COX inhibitor indomethacin affects DC phenotype, immature bone marrow derived DC were treated with LPS in the presence, or not, of indomethacin at two different concentrations for $24 \mathrm{~h}$.

DC phenotype was followed by flow cytometry (Figure 1). In all the cases, the percentage of positive cells expressing the cell surface markers, CD11c, CD40, CD80 and MHC II were similar in LPS-treated DC and in DC incubated with LPS and indomethacin, even at a high concentration of the COX inhibitor, as $10 \mu \mathrm{M}$. These results indicate that indomethacin does not interfere with DC maturation in vitro. Further experiment should be performance to evaluate this effect in vivo.

\subsection{NSAID Indomethacin Does Not Affect the Frequency of Splenic Immune Cell Populations in Balb/c and C57BL/6 Mice}

Once evaluated the effect of indomethacin on DC maturation in vitro, the possibility that the oral intake of this NSAID could affect the amount of splenic adaptive immune cells in vivo was checked. Given the genetic differences between $\mathrm{Balb} / \mathrm{c}$ and $\mathrm{C} 57 \mathrm{BL} / 6$ mice strains, this study was carried out on both strains of animals. For this purpose, naïve $\mathrm{C} 57 \mathrm{BL} / 6$ and $\mathrm{Balb} / \mathrm{c}$ mice were treated with 50 $\mu \mathrm{g} /$ mouse/day of indomethacin for three weeks. On days 7, 14 and 21, spleens from treated or untreated animals were removed and the amount of B cells, CD4+ and CD8+ T cells were assessed by flow cytometry.

Figure 2 shows the percentage of the adaptive immune cells isolated from spleens coming from $\mathrm{C} 57 \mathrm{BL} / 6$ and $\mathrm{Balb} / \mathrm{c}$ mice treated or not with indomethacin for the different days. As it is shown in the figure, the COX inhibitor had no impact on the cells evaluated in the spleen. These results were similar for both strains of mice.

\subsection{The Impact of Indomethacin in the Induction of OVA-Specific Antibodies Is Adjuvant-Dependent}

The effect of indomethacin on B cells functionality was assessed through the in- 
duction of an antigen specific antibody response. Balb/c mice were vaccinated with ovalbumin (OVA) in Complete Freund Adjuvant (OVA/CFA), with OVA in Alum (OVA/Alum), or with OVA in very small size proteoliposomes (VSSP). Quantification of OVA specific antibodies was performed by ELISA.

Figure 3 shows the optical densities ratios, representing the amounts of specific antibodies measured in the sera of animals with indomethacin and vaccinated and the amounts of these antibodies present in immunized animals just receiving drinking water. The administration of indomethacin resulted in a decrease of the anti-OVA total IgG antibodies in the two days evaluated (Figure 3(a)) for those animals that were immunized with OVA/CFA and OVA/Alum. As a tendency,
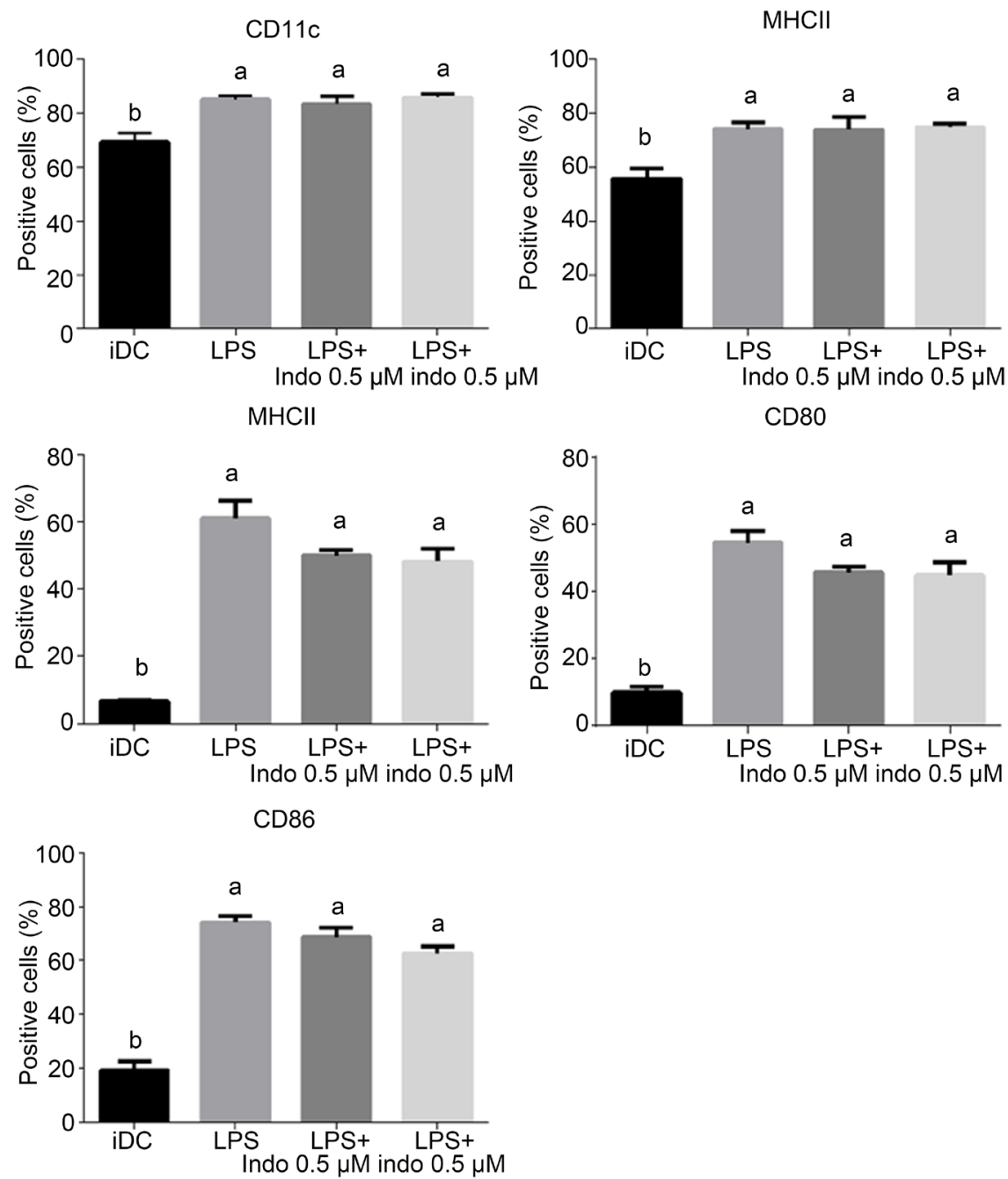

Figure 1. Cox inhibitor indomethacin does not affect BM-DC maturation in vitro. Immature BM-DCs were treated with LPS $(1 \mu \mathrm{g} / \mathrm{ml})$ with or without indomethacin $(0.5 \mu \mathrm{M}$ and $10 \mu \mathrm{M}$ ) for $24 \mathrm{~h}$. Graphs represent the \% of positive cells for cell surface markers CD11c, MHC II, CD40, CD80 and CD86. Cells were stained with Abs to cell surface markers and FACS analysis was performed. Column bars represent mean values \pm SEM. Statistical analyses were performed with one-way ANOVA and Tukey's Multiple Comparison Test, $\mathrm{p}<0.05$. Results are representative of two experiments with similar results. $\mathrm{Ab}$, antibody; BM-DC, bone marrow dendritic cells; imDC immature dendritic cells; Indo, indomethacin. 

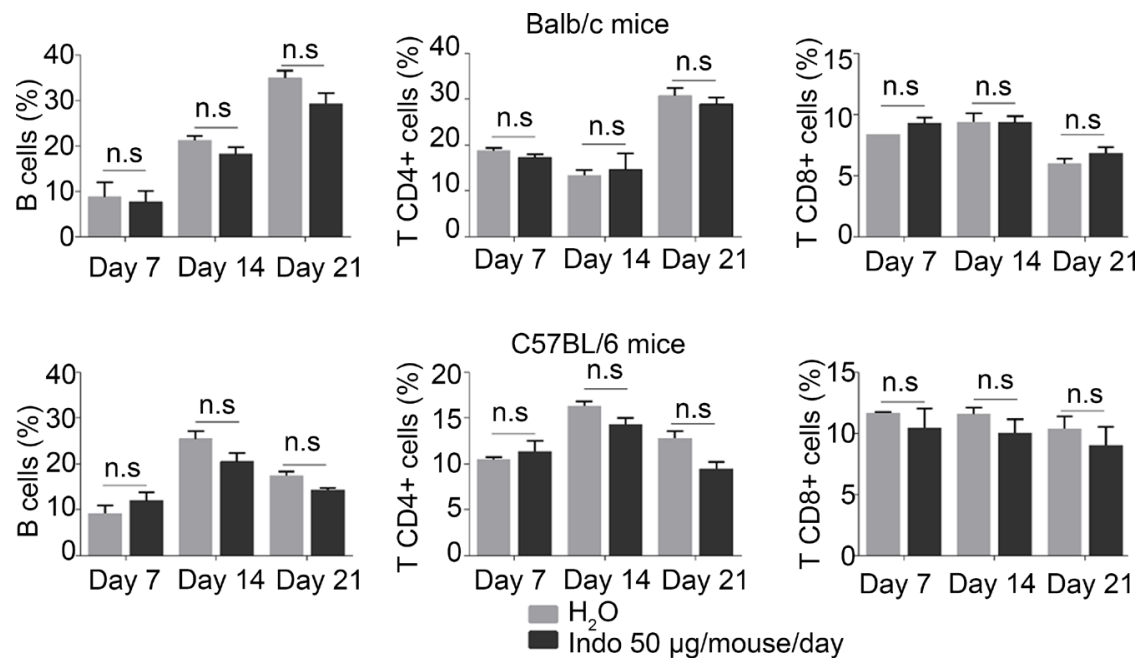

Figure 2. NSAID indomethacin do not change the frequency of adaptive immune cells in $\mathrm{Balb} / \mathrm{c}$ and $\mathrm{C} 57 \mathrm{BL} / 6$ mice. The frequencies of splenic $\mathrm{B}, \mathrm{CD} 4+$ and CD8+ T cells in Balb/c and $\mathrm{C} 57 \mathrm{BL} / 6$ mice, treated or not with indomethacin $(50 \mu \mathrm{g} / \mathrm{mouse} /$ day $)$ for 21 days were assessed by flow cytometry. Y-axis represents the $\%$ of positive cells for the different populations in the spleen. Column bars represent mean values of three mice \pm SEM. Statistical analyses were performed with Mann-Whitney $U$ test, $p<0.05$. Results are representative of two experiments with similar results. Indo, indomethacin. SEM, standard error of the mean.

this decrease was more pronounced in those mice immunized with OVA/Alum. However, mice receiving indomethacin and vaccinated with OVA/VSSP did not show changes in the antibody response. The study of the different antibody subclasses showed similar results. There was a decrease for anti-OVA IgG1 antibodies (Figure 3(b)) in mice immunized with OVA/CFA or OVA/Alum, but not in those animals immunized with OVA/VSSP. In general, a similar tendency was observed for IgG2a (Figure 3(c)) and IgG2b subclasses (Figure 3(d)), suggesting that the COX inhibitor indomethacin interfere with $\mathrm{B}$ cells function by affecting the induction of antigen specific antibodies in adjuvant dependent way.

\subsection{The Interference of COX Inhibitor Indomethacin on Cytotoxic CD8+ T Cell Response Is Adjuvant-Dependent}

Next, a possible interference of indomethacin on CTL activity was explored in vaccinated mice. For this purpose, an in vivo CTL assay was performed by immunizing mice with OVA and VSSP (OVA/VSSP) or OVA and polyinosinic-polycytidylic acid as adjuvant (OVA/Poly I:C). Both adjuvants are especially suited for Th1 polarization and promoters of CTL response [32] [40]. Noteworthy, immunization of mice while receiving indomethacin with OVA/Poly I:C resulted in a 55\% decrease of antigen specific lysis, compared with the control group (Figure 4). However, in mice vaccinated with OVA/VSSP, irrespective if were treated or not with indomethacin, the stimulated specific CD8+ T cells exhibited similar lytic capacity. These data suggest that the effect of the COX inhibitor indomethacin on CTL-response will depend on the adjuvant used. 

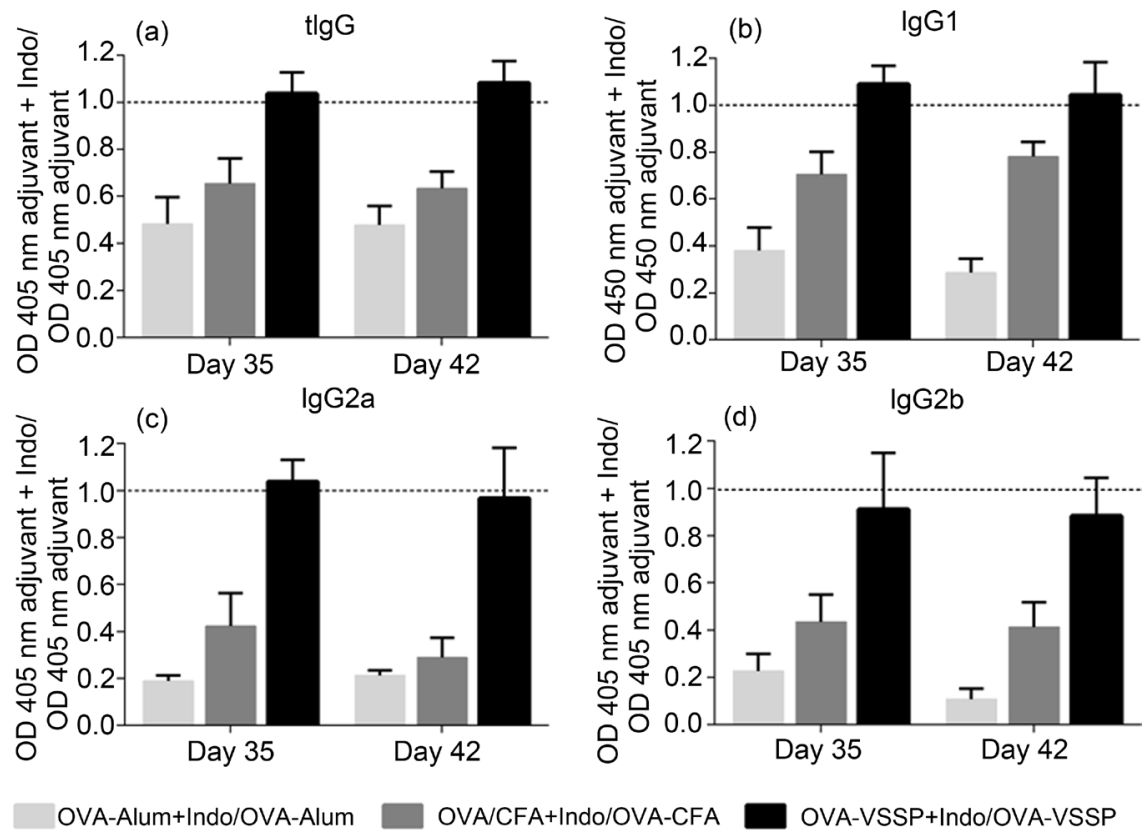

Figure 3. Indomethacin affects the humoral response in mice immunized with OVA/CFA or OVA/Alum, but do not interfere with VSSP action. Balb/c mice were immunized thrice with OVA/CFA, OVA/Alum or OVA/VSSP on days 0,14 and 28. Sera were obtained on days 21,35 and 42 . Indomethacin at $50 \mu \mathrm{g} /$ mouse/day was added in the drinking water since day 0 until the end of the experiment. Graphs represent the relation between the response obtained in the presence of the adjuvant + indomethacin and the adjuvant alone. (a): OVA-specific total IgG response. (b): OVA-specific IgG1 response. (c): OVA-specific IgG2a response. (d): OVA-specific IgG2b response. Dashed lines indicate the value in which there is not an affectation of the antibody response. Column bars represent mean values of five mice \pm SEM. Results are representative of two experiments with similar results. OD, optical density; Indo, Indomethacin; CFA, Complete Freud Adjuvant.

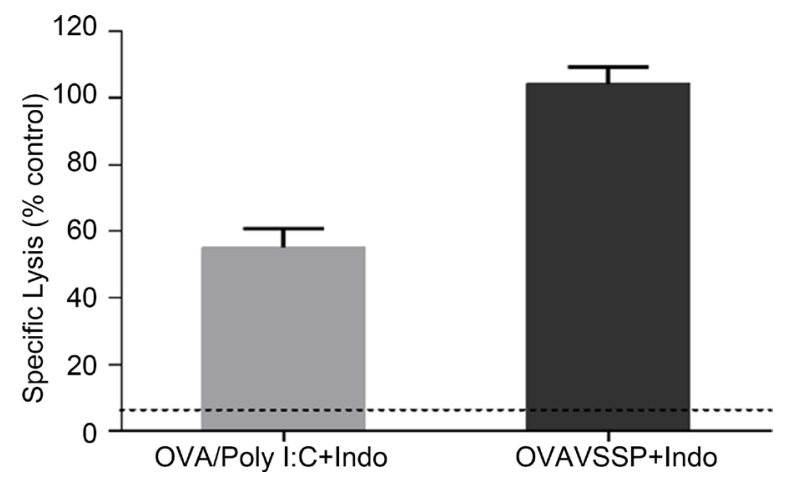

Figure 4. COX inhibitor indomethacin affects the cytotoxic CD8+ $\mathrm{T}$ cells response in mice immunized with OVA/Poly I:C but does not interfere with VSSP action. C57BL/6 mice were immunized three times with OVA/Poly I:C or OVA/VSSP. Indomethacin at 50 $\mu \mathrm{g} /$ mouse/day was added to the drinking water since 14 days before the priming and kept until the end of the experiment. Nine days after starting immunizations, mice were injected intravenously with equal amounts of SIINFEKL-pulsed or control splenocytes differentially stained with CFSE. Each bar corresponds to the ratio between the mean of the percent of specific lysis induced in three individual mice taking indomethacin and other three littermates just drinking water. Dashed line indicates the reference value corre experiments with similar results. Indo, indomethacin; OVA; ovalbumin. SEM, standard error of the mean. 
3.5. The Antitumor Effect of the NSAID Indomethacin in the 3LL-D122 Tumor Model Is Not Mediated by CD4+ or CD8+T Cells

After observing a decrease in the specific CTL effector function in mice chronically treated with indomethacin, the next question was if this impairment affects the antitumor effect of this NSAID. In further experiments 3LL-D122 lung tumor bearing mice received indomethacin at a final concentration of $50 \mu \mathrm{g} /$ mouse/day during all the experiment.

A significant relative reduction of the tumor volume (Figure 5(a)) was evident in animals under the COX inhibitor treatment. Then to assess if the acquired immunity effector $\mathrm{T}$ cells are involved in this antitumor effect, the experiment of Figure 5(a) was repeated but depleting in the mice CD4+ or CD8+ T cells. Interestingly, indomethacin conserved its full antitumor activity even in the absence of CD4+ or CD8+ T cells, suggesting a minimal, if any, influence of these immune cells in the effect of this drug at least in this model (Figure 5(b)).

\subsection{The in Vivo Antitumor Effect of Indomethacin Does Not Correlate with Levels of PGE2 Secretion by Tumor Cell Lines in Vitro}

In order to check if other solid tumor models were sensitive to the COX inhibitor indomethacin, as was the case of 3LL-D122 tumors, Balb/c mice were challenged with the mammary carcinoma tumor $4 \mathrm{~T} 1$ or the colon carcinoma tumor

(a)

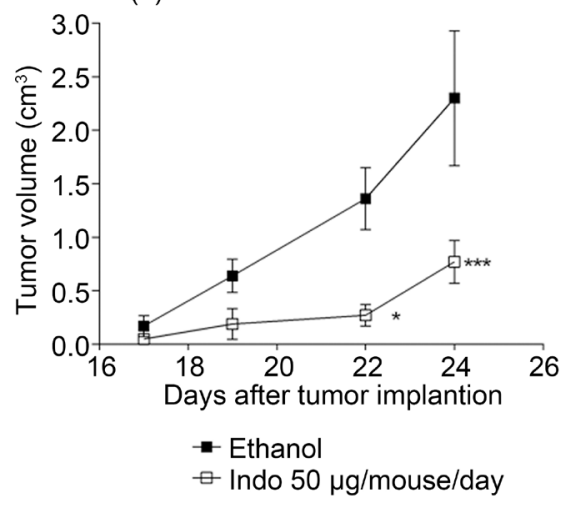

(b)

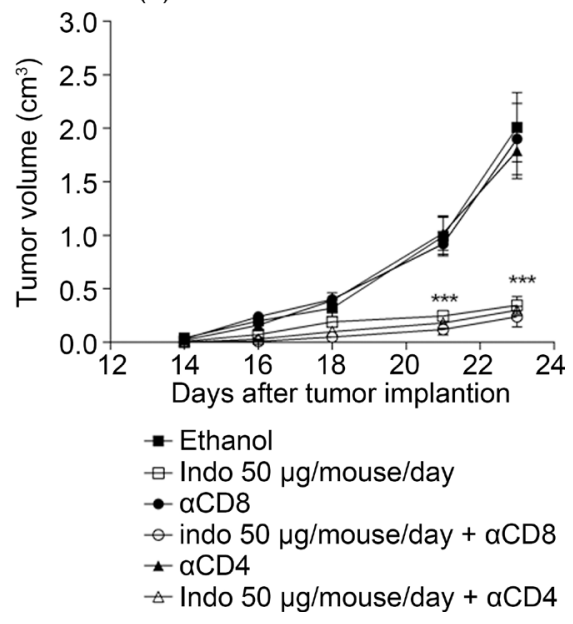

Figure 5. The antitumor effect of the NSAID indomethacin on 3LL-D122 SC tumors is independent of $\mathrm{CD} 4+$ and $\mathrm{CD} 8+\mathrm{T}$ cells. C57BL/6 mice were challenged with 3LL-D122 $\left(2 \times 10^{5}\right.$ cells $)$ into the right hind footpad. Indomethacin was given since day 0 until the end of the experiment in the drinking water. (a): 3LL-D122 tumor volume in mice treated with indomethacin. (b): Tumor growth in mice treated with indomethacin and depleted of $\mathrm{CD} 4+$ or $\mathrm{CD} 8+\mathrm{T}$ cells. The mean of 10 individual mice \pm SEM was represented in each point. Statistical analyses were performed with one-way ANOVA and Tukey's Multiple Comparison Test for each day, ${ }^{*} \mathrm{p}<0.05,{ }^{* *} \mathrm{p}<0.01,{ }^{* *} \mathrm{p}<0.001$ referred to the control group. Results are representative of one experiment repeated twice with similar results. Indo, Indomethacin; $\alpha \mathrm{CD} 4$, anti- $\mathrm{CD} 4$ monoclonal antibody; $\alpha \mathrm{CD} 8$, anti-CD8 monoclonal antibody; SEM, standard error of the mean. 
CT26, and C57BL/6 mice with B16-F10 melanoma or lung epithelial tumor TC1. In all cases mice were exposed to indomethacin $(50 \mu \mathrm{g} / \mathrm{mouse} / \mathrm{day})$ until the end of the experiment. Tumor volume was measured three times a week. As expected, not all the tumor models were sensitive to the drug (Figure 6). In 4T1 tumor bearing mice indomethacin didn't show any effect on tumor growth (Figure 6(a)), while in animals inoculated with CT26 cells the NSAID significantly reduced tumor volume (Figure 6(b)). A similar behavior was observed in C57BL/6 tumor bearing mice. The COX inhibitor didn't impact on tumor growth in MB16-F10 model but significantly reduced tumor volume in TC1 tumor bearing mice (Figure 6(c) and Figure 6(d)). To determine if the different outcome of the drug in each tumor model is associated with the capacity of these tumor cells to secrete PGE2 in vitro, individual cell lines were cultured for 24 hours and PGE2 was quantified in the supernatants by ELISA (Figure 6(e)). A significant amount of PGE2 was detected in CT26 (276.6 $\pm 54.3 \mathrm{ng} / 106$ cells), 4T1 (166.9 $\pm 17.2 \mathrm{ng} / 106$ cells) and 3LL-D122 (147.2 $\pm 30.0 \mathrm{ng} / 106$ cells) cell lines. TC1 and MB16-F10 cells produced as an average 50-fold less prostaglandin $(1.9 \pm 1.5 \mathrm{ng} / 106$ cells and $1.6 \pm 1.4 \mathrm{ng} / 106$, respectively). Curiously, even when TC1 cells almost didn't secrete PGE2, indomethacin showed a significant impact on tumor growth when these cells were implanted in mice. On the contrary, in mice treated with this NSAID no antitumor effect was observed after 4T1 cells' transplant, even when these cells produce large amounts of PGE2. Overall, these results suggest the absence of an absolute conditioning of the antitumor effect of indomethacin to the direct capacity of tumor cells to secrete PGE2.

\subsection{Combining the COX Inhibitor Indomethacin with an E7 Peptide/VSSP Vaccine Abrogates the Antitumor Effect of the Drug in TC1 Tumors}

Once defined an antitumor effect of indomethacin in certain tumor models, a possible potentiation of this effect by selected VSSP based cancer vaccines was evaluated. VSSP is a peculiar adjuvant system characterized by its capacity to induce and sustain specific CTL responses in severe immune compromised hosts [34]. A first selected model for this experiment was the lung carcinoma TC1, based in a previous report (Torrens et al. in 2005) of an outstanding in vivo effect of the (RAHYNIVTF) E7peptide/VSSP vaccine (E7p/VSSP) in this type of tumor, combined with its sensitivity to indomethacin. Figure 7 (a) shows the results of the refinement of the previous antitumor experiment, in which mice were inoculated by subcutaneous way with $2 \times 10^{5}$ TC1 cells and immunized twice with the vaccine evidenced a significant reduction on tumor volume compared to the unvaccinated littermates. In similarly treated animals, but challenged with $10^{6} \mathrm{TC} 1$ cells, the effect of vaccination over tumor growth was lost. This more astringent setting was selected for conducting the combination experiments.

Mice were challenged with $10^{6}$ TC1 tumor cells and immunized with the E7p/VSSP vaccine when tumors reached $4 \mathrm{~mm}$ of diameter. A second vaccination was performed 14 days later, while indomethacin administration started at 
(a)

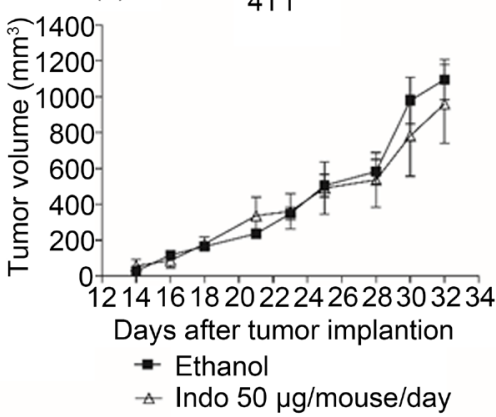

(c)

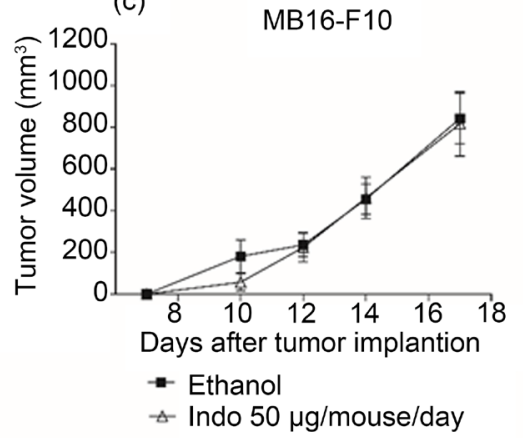

(b)

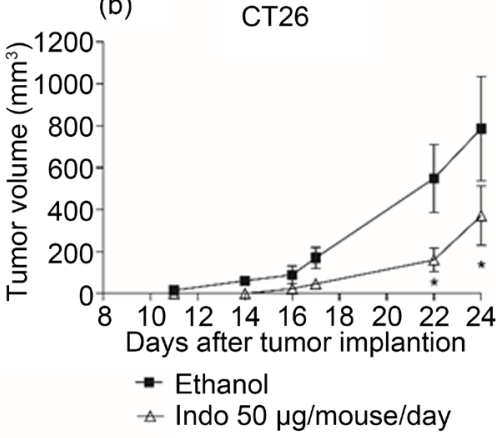

(d)

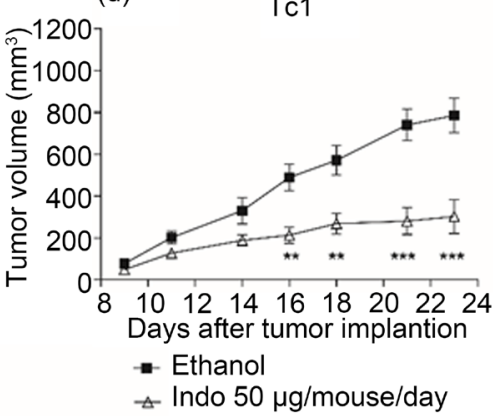

(e)

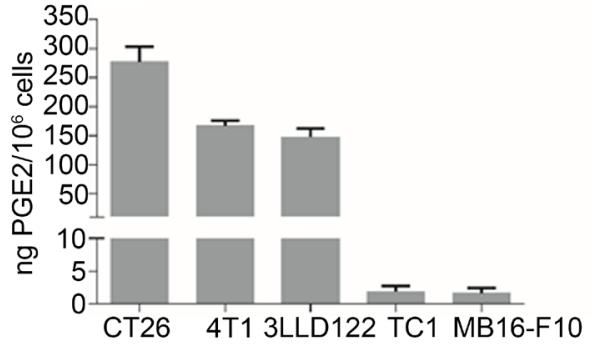

Figure 6. PGE2 secretion in vitro does not correlate with the antitumor effect of indomethacin in different tumor models. Balb/c mice were challenged SC with 4T1 or CT26 cell lines ( $\mathrm{a}$ and $\mathrm{b}$ ), while C57BL/6 mice with MB16-F10 or TC1 cell lines ( $\mathrm{c}$ and $\mathrm{d}$ ). Animals were treated with $50 \mu \mathrm{g} /$ mouse/day of the drug since day 0 until the end of the experiment and tumor volume measured in the week. Each point represents the mean of 10 individual mice \pm SEM. Statistical analyses were performed with a t-Student Test for each day, ${ }^{*} \mathrm{p}<0.05,{ }^{* *} \mathrm{p}<0.01,{ }^{* * *} \mathrm{p}<0.001$ referred to the control group. (e): PGE2 in the collected supernatants of tumor cell lines cultures after $24 \mathrm{~h}$, assessed by ELISA. Each bar represents the mean \pm SEM. Results are representative of two experiments. Indo, Indomethacin; PGE2, prostaglandin E 2; SEM, standard error of the mean; SC subcutaneously.

the same time of the first immunization and was maintained until the end of the experiment. As expected, tumor growth in the vaccinated group was similar to the control group in which mice received PBS (Figure $7(b)$ ). On the contrary indomethacin uptake provoked a significant reduction in tumor volume on days 16, 21 and 23. Surprisingly, when animals treated with indomethacin were immunized with the E7p/VSSP vaccine, the antitumor effect of the drug was completely abolished. This unexpected result is an infrequent case in which active immunotherapy interfere with the antitumor effect of a drug. 
(a)

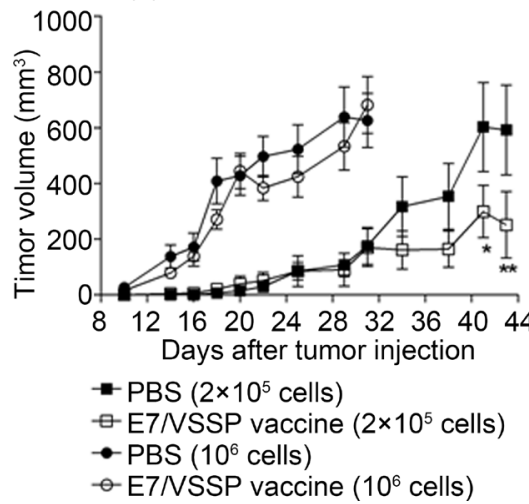

(b)

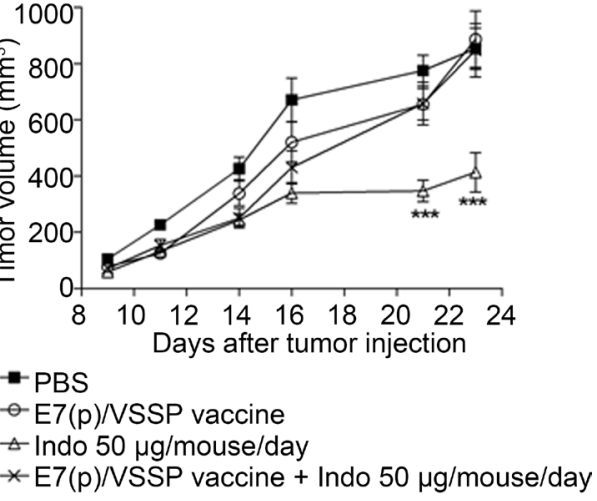

Figure 7. E7p/VSSP and indomethacin combination abrogates the antitumor effect of the drug in the TC1 subcutaneous model. C57BL/6 mice were challenged with TC1 cell line. E7p/VSSP vaccine was subcutaneously administered at day 10 and 24. (a): Tumor volume of TC1 tumor bearing mice vaccinated with E7(p)/VSSP vaccine. Mice were challenged with two different concentrations of TC1 cell line and were vaccinated twice. Each point represents the mean of 10 individual mice \pm SEM of tumor volume. Statistical analyses were performed with a t-Student Test for each day, ${ }^{*} \mathrm{p}<0.05$, ${ }^{* *} \mathrm{p}<0.01$. (b): Tumor volume of TC1 tumor bearing mice vaccinated and treated with indomethacin. The treatment with indomethacin started on day 10 and was maintained, in the drinking water, until the end of the experiment. Each point represents the mean of 20 individual mice \pm SEM of tumor volume. Statistical analyses were performed with one-way ANOVA and Tukey's Multiple Comparison Tests, ${ }^{* *} \mathrm{p}<0.001$, referred to the control group. Results are representative of two experiments with similar results. Indo, Indomethacin; SEM, standard error of the mean.

\subsection{Simultaneous Administration of the NSAID Indomethacin and the NGcGM3/VSSP Vaccine Not Only Maintained the Effect of the Drug on Primary 3LL-D122 Tumor Growth but Also Potentiated Its Antimetastatic Effect}

To address if the observed interference of a VSSP based vaccine with indomethacin's antitumor effect in the TC1 tumor model could be generalized, a combination of the COX inhibitor with the NGcGM3/VSSP vaccine in the 3LL-D122 spontaneous lung metastasis model was experimented. This two steps model consists first in the primary tumor growth, followed by a metastatic widespread into the lungs after the surgical removal of the tumor. Seven and twenty-one days after inoculating mice with 3LL-D122 tumor cells in the footpad, the NGcGM3/VSSP vaccine was injected by SC route. Indomethacin $(25 \mu \mathrm{g} /$ mouse/day) was administrated in the drinking water since day 0 until the end of the experiment. While in the vaccinated group primary tumor development was similar than that observed in animals just injected with buffer, the treatment of mice with indomethacin resulted in a significant reduction of tumor volume, reproducing the previous disclosed results (Figure 7(a)). On the other hand, in mice simultaneously vaccinated and treated with the COX inhibitor the antitumor effect of the drug was totally conserved, thought a potentiated antitumor result, associated to this combination, was not produced.

Finally, a possible option of potentiated effect of the NGcGM3/VSSP and indomethacin combination was tested in the spontaneous metastasis step of the 
3LLD122 lung carci-noma model. When tumors on the mice footpad reached about $0.8 \mathrm{~cm}$ of diameter, they were removed by surgery and twenty-one days later the animals were sacrificed and the metastatic spread assessed through the lungs weights as a surrogate parameter (Figure 8). After surgery, the indomethacin supply was suspended and restored one week later. As usual immunization of tumor bearing mice with the NGcGM3/VSSP vaccine resulted in a significant reduction in lungs' weights $(0.64 \pm 0.24 \mathrm{~g})$, compared with the control group that received PBS $(1.11 \pm 0.24 \mathrm{~g})$ [39]. Similar to the result of the vaccinated group, mice treated with the COX inhibitor indomethacin showed also a significant decrease in lung weights $(0.60 \pm 0.34 \mathrm{~g})$, while the same behavior was appreciated in mice immunized and treated with indomethacin $(0.46 \pm 0.14 \mathrm{~g})$. No statistical differences were found between the immunized group that received the COX inhibitor and the groups that just were treated with indomethacin or the vaccine. However, considering as a reference value the mean of the lung weights from the vaccinated group $(0.64 \mathrm{~g})$, the $62 \%$ of the mice treated with indomethacin showed lung weights under this value while just the $47 \%$ of the lung weights from the vaccinated group were under $0.64 \mathrm{~g}$ (Table 1).

(a)

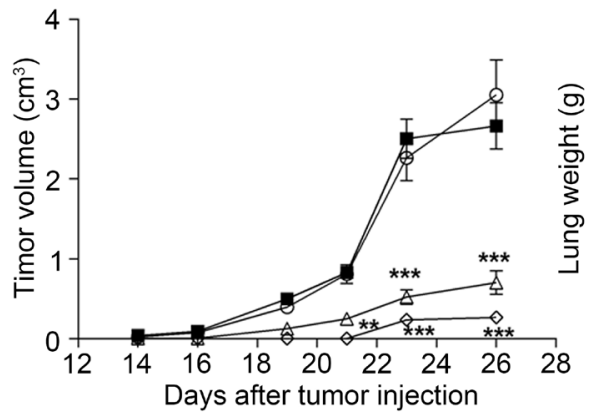

- PBS

- NGcGM3/NSSP vaccine

$\triangle$ Indo $50 \mu \mathrm{g} / \mathrm{mouse} / \mathrm{day}$

$\rightarrow$ Indo $50 \mu \mathrm{g} / \mathrm{mouse} / \mathrm{day}+\mathrm{NGcGM3/NSSP}$ vaccine (b)

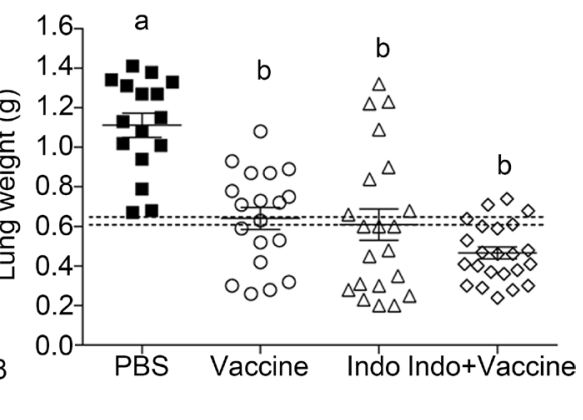

Figure 8. The combination of indomethacin with the NGcGM3/VSSP vaccine does not improve the effect of the drug over primary tumor growth in the 3LL-D122 spontaneous tumor model. C57BL/6 mice were challenged with 3LL-D122 cells into the right hind footpad. The NGcGM3/VSSP vaccine was administered on days 7 and 21 and indomethacin supplied at $25 \mu \mathrm{g} /$ mouse/day. Tumor growth was assessed thrice a week. Each point represents the mean of tumor volume corresponding to 15 individual mice \pm SEM. Statistical analyses were performed with one-way ANOVA and Tukey's Multiple Comparison Tests, ${ }^{* *} \mathrm{p}<0.01,{ }^{* * *} \mathrm{p}<0.001$ referred to the control group. (b): Lung weight. Twenty-one days after primary tumor surgery, mice were sacrificed and the lungs were extracted and weighted. Indomethacin uptake was initiated one week after surgery and maintained until the end of the experiment. Graph shows the individual values of lung weight from each mouse and the mean value \pm SEM. Dash lines indicates the mean values of lung weights corresponding to both groups of animals just treated with indomethacin or vaccine. Statistical analyses were performed with one-way ANOVA and Tukey's Multiple Comparison Test. Different letters indicate statistical differences. Results are representative of two independent experiments with similar results. Indo, Indomethacin; SEM, standard error of the mean. 
Table 1. The combination of indomethacin with the NGcGM3/VSSP vaccine resulted in the highest number of lung weights above the media of the vaccinated group.

\begin{tabular}{ccccc}
\hline \multirow{2}{*}{ Results } & \multicolumn{4}{c}{ Treatment } \\
\cline { 2 - 5 } & PBS & Vaccine & Indomethacin & $\begin{array}{c}\text { Vaccine }+ \\
\text { Indomethacin }\end{array}$ \\
\hline $\begin{array}{c}\text { Above 0.64 g } \\
\text { (vaccine group media) } \\
\text { Below 0.64 g } \\
\begin{array}{c}\text { (vaccine group media) } \\
\text { Total of mice per } \\
\text { group }\end{array}\end{array}$ & $100 \%^{\mathrm{a}}(16)$ & $53 \%^{\mathrm{b}}(10)$ & $38 \%^{\mathrm{b}}(8)$ & $13 \%^{\mathrm{c}}(2)$ \\
\hline
\end{tabular}

Different letters indicate statistical differences according to Chi-square test.

Interestingly, the $87 \%$ of the mice that received the COX inhibitor indomethacin and the NGcGM3/VSSP vaccine exhibit lung weights under the mean of the vaccinated group, distribution with statistical difference according to Chi-square test. Together these results indicate that the combination of both treatments resulted in a better antimetastatic effect than the vaccine alone.

\section{Discussion}

Cancer vaccines represent the major form of active immunotherapy intended to activate the endogenous tumor antigen-specific response. Up until now, one of the most challenging $\mathrm{t}$ asks is to design anti-cancer vaccines accompanied by pharmacological strategies able to break the immunosuppressive barrier of the tumor microenvironment [3]. A variety of therapies have been evaluated for this purpose, including pharmacological, biological and metabolic agents [41]. Especially, the immunotherapeutic manipulation of COX-2/PGE2 signaling using NSAIDs is a very promising strategy; however, there are only a few studies about the impact of these NSAIDs on the immune response to vaccination as well about the cells involved in this response

DC, as the professional antigen-presenting cells, plays an essential role in the developing of antitumor immune responses [3]. Because of this, in the present study we evaluated the cell viability and phenotype of murine DC in presence of NSAIDs, specifically, indomethacin. The incubation of DC with a low dose of indomethacin did not change the number of DC or its phenotype assessed as the expression of the cell surface markers CD11c, MHC II, CD40, CD80 and CD86. This result was in accordance with a previous study made by Harizi in 2001, in which they demonstrated that the incubation with indomethacin did not change the number of murine DC in vitro. On the other hand, Harizi et al in 2002 demonstrated that the phenotype of DC matured in the presence of indomethacin, was not affected [42]. However, different to these previous studies, we evaluated also a higher dose of indomethacin. Interestingly, we observed that even at this high dose, the cell viability and the expression of cell surface markers were similar to the untreated control. The higher dose evaluated in this work is closer to those doses using in the in vivo experiments in mice. These results supported the idea that the treatment with indomethacin does not affect the DC 
in vivo. Further experiments will be carried out in order to answer this.

Besides the antigen presenting cells, B, CD4+ and CD8+ T cells are crucial, for the immune response to the vaccination. However, there are few studies about the impact of NSAIDs on the frequency of these cell populations and the most part of them just involved COX-2, either alone or in combination with vaccines. These studies have been demonstrated that these specific inhibitors can increase the tumor site infiltration of $\mathrm{CD} 4+$ and $\mathrm{CD} 8+\mathrm{T}$ cells, thereby positively regulating the tumor specific host immune response against cancer [12]-[17]. In this work, we evaluated the frequency of $\mathrm{B}, \mathrm{CD} 4+$ and CD8+ T cells in healthy Balb/c and $\mathrm{C} 57 \mathrm{BL} / 6$ mice under treatment with indomethacin for three weeks. Indomethacin did not affect the frequency of CD4+ T cells in neither of both mice strains. On the contrary, B cell population showed a slight reduction until the second week of treatment even in the Balb/c mice as well in the C57BL/6 mice. In this last strain, CD8+ T cells were also reduced after two weeks of treatment. The difference between our results and the previous studies may be explained in part for the presence of an established tumor. Tumor-derived COX-2/PGE2 signaling is closely allied to the induction as well as the increased activity of CD4+ CD25+ FOXP3+ $\mathrm{T}$ regulatory cells ( $\mathrm{T}$ reg) [20] [43]. NSAIDs may suppress $\mathrm{T}$ reg activation in these tumor settings, and thus promote CD4+ and CD8+ T cell infiltration [3].

We evaluated also the functionality of B cells in the presence of indomethacin through the induction of an antigen specific antibody response. We observed that Balb/c mice immunized three times with OVA and the combine Th1/Th2 adjuvant CFA or with the Th2 adjuvant Alum, showed a decrease in total anti-OVA IgG antibodies even two weeks after the last immunization. This reduction was also observed for the anti-OVA IgG1, IgG2a and IgG2b antibodies sub classes. However, the induction of anti-OVA antibodies by the immunization with OVA/VSSP was not affected by the treatment with indomethacin. Previous, in vivo studies had been demonstrated that mice immunized once with OVA/CFA and treated for three weeks with indomethacin showed a decrease in total anti-OVA IgG antibodies as well in the anti-OVA IgG1 and anti-OVA IgG2a antibodies [44]. Our present study is in accordance whit the previous result, but also includes a similar evaluation for two different adjuvants, as Alum and VSSP showing that the effect on the humoral response seems to depend on the adjuvant type.

On the other hand, T cells, in particular the CD8+ CTLs, are considered the major contributors to the effectors mechanisms of antitumor immunity [45]. The principal element of antitumor immunity is, in fact, the surveillance function of CTLs, whereby they recognize and kill potentially malignant MHC-I-positive cells. The effects of NSAIDs on the CTL response have been mainly assessed on in vitro experiments [46]. In our study, we evaluated the impact of indomethacin on the CTL response in mice immunized with OVA/Poly I:C or OVA/VSSP. Both adjuvants are especially suited for Th1 polarization and promoters of CTL response [32] [40]. We observed that indomethacin provoked a reduction of an- 
tigen specific lysis of the effectors generated by the immunization with OVA/Poly I:C. Interestingly, when mice were vaccinated with OVA/VSSP, the antigen specific lysis was maintained. A previous work by Oliver et al in 2012, demonstrated that a VSSP-based OVA vaccine induced a normal antigen-specific CTL response in mice rendered leukopenia by the administration of high doses of the chemotherapeutic agent cyclophosphamide [34]. Thus, indomethacin may act different in the generation of an immune response to vaccination depending on the adjuvant use in the vaccine. Nevertheless, VSSP-based cancer vaccines seem to be a good selection to combine with NSAIDs.

On the other hand, some studies have revealed that NSAIDs may up-regulate the antitumor immune response by enhancing the $\mathrm{T}$ cell number or function in the tumor site [47] [48] [49] [50]. However, the relation of the antitumor effect of indomethacin and the participation of $\mathrm{CD} 4+$ and $\mathrm{CD} 8+\mathrm{T}$ cells has been poorly studied.

In a previous work in mice inoculated with the murine mammary tumor cell line 410.4 and treated with indomethacin, the depletion of CD4+ or CD8+ T cells lead to the loss of the antitumoral effect of indomethacin in this model [51]. We studied this in the murine lung carcinoma cell line 3LL-D122, model in which there is has been previously reported that indomethacin has an antitumoral effect on tumor bearing mice [52] [53] [54] [55]. Curiously, when we administrated specific antibodies to deplete $\mathrm{CD} 4+$ and $\mathrm{CD} 8+\mathrm{T}$ cells, the antitumoral effect of indomethacin was maintained. Thus, requirement of $\mathrm{T}$ cells in the antitumoral effect of indomethacin may depend on the tumor type as well as the localization.

In some models as the colon carcinoma CT26 and the mammary carcinoma 4T1, NSAIDs, specifically, indomethacin, also have shown antitumoral effects [56] [57]. On the other hand, in the lung epithelial tumor TC1 the selective inhibition of COX-2 did not have any antitumoral effect [17]. Even more, it have been reported that indomethacin augmented de frequency of MB16 tumor bearing mice [58].

In our study, we observed an antitumoral effect for TC1 and CT26 tumor bearing mice. However, the treatment with indomethacin did not showed any effect in the tumor growth in the 4T1 and MB16 models. We assessed if this differential effect on the tumor growth was to the ability of these tumor cells of secrete naturally PGE2. We found out that even when indomethacin had a significant antitumoral effect in the TC1 model, these cells did not secrete PGE2 in vitro. As well, the 4T1 cell line secretes large levels of this cytokine but however indomethacin had no any effect on tumor growth in vivo. Together these results may indicate that indomethacin may act different on tumor growth depending on the tumor cell type and this effect is independent of the capacity of the cells of secrete PGE2 themselves in vitro trough a COX-independent way.

We also demonstrated in our study that the combinations between different cancer vaccines and NSAIDs may have different outcomes. Because of the results obtained from our experiment we choose VSSP-based cancer vaccine for the 
combination therapies. For TC1 subcutaneous model, it had previously described that the E7p/VSSP vaccine had a significant antitumoral effect on tumor growth [31]. Unexpectedly, we observed that when indomethacin and the E7p/VSSP are combined in an experimental set where the vaccine does not work, the antitumoral effect of this NSAID is complete abolished. However, in the 3LL-D122 model, the combination of indomethacin with the NGcGM3/VSSP vaccine did not lead to an abolishment of the effect of the drug but did not produce either a potentiation of the effect of the vaccine. On the contrary, the administration of indomethacin in the 3LL-D122 metastatic scenario lead to an augment of the antimetastatic effect of the NGcGM3/VSSP vaccine reported previously for this model, related to the percentage of individual beneficed [39].

Together, these results may indicate that the combination of NSAIDs, specifically indomethacin with cancer vaccines, may have different results in dependence of the cancer vaccine type, as well as the tumor model. These differences observed between the no-selective inhibitors and the selective one may be due to its different mechanisms of actions. There have been described many mechanism for NSAIDs that are independent of COX-2 [23] [24] [25] [26] [27], that implicate COX-1-dependent ways as well as pathways different of COX/PGE2. Because of all potentialities that have the use of NSAIDs in combination of with cancer vaccines, the study of the underlying mechanisms to explain the different outcomes observed in this work, is extremely necessary for the right selection of a proper strategy to enhance an effective antitumor response.

\section{Conclusion}

Overall, our results demonstrate that NSAIDs affect the humoral and the cellular response in mice immunized with OVA/CFA, OVA/Alum or OVA/Poly I:C, but do not interfere with VSSP effect. Our results also suggest that PGE2 secretion does not correlate with the antitumoral effect of indomethacin in different tumor models and this effect does not depend on CD4+ T or CD8+ T cells. Finally, this study corroborates that COX inhibitors can be used in combination with cancer vaccines but the final outcome will depend on the tumor model and the vaccine used.

\section{References}

[1] Mocellin, S., Mandruzzato, S., Bronte, V., Lise, M. and Nitti, D. (2004) Part I: Vaccines for Solid Tumours. The Lancet Oncology, 5, 681-689. https://doi.org/10.1016/S1470-2045(04)01610-9

[2] Ostrand-Rosenberg, S., Sinha, P., Danna, E.A., Miller, S., Davis, C. and Dissanayake, S.K. (2004) Antagonists of Tumor-Specific Immunity: Tumor-Induced Immune Suppression and Host Genes That Co-Opt the Anti-Tumor Immune Response. Breast Disease, 20, 127-135. https://doi.org/10.3233/BD-2004-20113

[3] Hussain, M., Javeed, A., Ashraf, M., Al-Zaubai, N., Stewart, A. and Mukhtar, M.M. (2012) Non-Steroidal Anti-Inflammatory Drugs, Tumour Immunity and Immunotherapy. Pharmacological Research, 66, 7-18. https://doi.org/10.1016/j.phrs.2012.02.003

[4] Stewart, T.J. and Smyth, M.J. (2011) Improving Cancer Immunotherapy by Target- 
ing Tumor-Induced Immune Suppression. Cancer and Metastasis Reviews, 30, 125 140. https://doi.org/10.1007/s10555-011-9280-5

[5] Vane, J.R. (1971) Inhibition of Prostaglandin Synthesis as a Mechanism of Action for Aspirin-Like Drugs. Nature: New Biology, 231, 232-235.

https://doi.org/10.1038/newbio231232a0

[6] Lipsky, P.E. (1999) Role of Cyclooxygenase-1 and -2 in Health and Disease. The American Journal of Orthopedics, 28, 8-12.

[7] Adelizzi, R.A. (1999) COX-1 and COX-2 in Health and Disease. The Journal of the American Osteopathic Association, 99, S7-S12.

https://doi.org/10.7556/jaoa.1999.99.11.S7

[8] Zha, S., Yegnasubramanian, V., Nelson, W.G., Isaacs, W.B. and De Marzo, A.M. (2004) Cyclooxygenases in Cancer: Progress and Perspective. Cancer Letters, 215, 120. https://doi.org/10.1016/j.canlet.2004.06.014

[9] Dai, Y. and Wang, W.H. (2006) Non-Steroidal Anti-Inflammatory Drugs in Prevention of Gastric Cancer. World Journal of Gastroenterology, 12, 2884-2889. https://doi.org/10.3748/wjg.v12.i18.2884

[10] Ulrich, C.M., Bigler, J. and Potter, J.D. (2006) Non-Steroidal Anti-Inflammatory Drugs for Cancer Prevention: Promise, Perils and Pharmacogenetics. Nature Reviews Cancer, 6, 130-140. https://doi.org/10.1038/nrc1801

[11] Pereg, D., Kimhi, O., Tirosh, A., Orr, N., Kayouf, R. and Lishner, M. (2005) The Effect of Fermented Yogurt on the Prevention of Diarrhea in a Healthy Adult Population. American Journal of Infection Control, 33, 122-125.

https://doi.org/10.1016/j.ajic.2004.11.001

[12] Lang, S., et al. (2007) Immune Restoration in Head and Neck Cancer Patients after in Vivo COX-2 Inhibition. Cancer Immunology, Immunotherapy, 56, 1645-1652. https://doi.org/10.1007/s00262-007-0312-5

[13] Hahn, T., et al. (2006) Short-Term Dietary Administration of Celecoxib Enhances the Efficacy of Tumor Lysate-Pulsed Dendritic Cell Vaccines in Treating Murine Breast Cancer. International Journal of Cancer, 118, 2220-2231. https://doi.org/10.1002/ijc.21616

[14] Dovedi, S.J., Kirby, J.A., Davies, B.R., Leung, H. and Kelly, J.D. (2008) Celecoxib Has Potent Antitumour Effects as a Single Agent and in Combination with BCG Immunotherapy in a Model of Urothelial Cell Carcinoma. European Urology, 54, 621-630. https://doi.org/10.1016/j.eururo.2008.01.013

[15] Talmadge, J.E., Hood, K.C., Zobel, L.C., Shafer, L.R., Coles, M. and Toth, B. (2007) Chemoprevention by Cyclooxygenase-2 Inhibition Reduces Immature Myeloid Suppressor Cell Expansion. International Immunopharmacology, 7, 140-151. https://doi.org/10.1016/j.intimp.2006.09.021

[16] Lonnroth, C., et al. (2008) Preoperative Treatment with a Non-Steroidal Anti-Inflammatory Drug (NSAID) Increases Tumor Tissue Infiltration of Seemingly Activated Immune Cells in Colorectal Cancer. Cancer Immunity, 8, 5.

[17] Haas, A.R., et al. (2006) Cycloxygenase-2 Inhibition Augments the Efficacy of a Cancer Vaccine. Clinical Cancer Research, 12, 214-222.

https://doi.org/10.1158/1078-0432.CCR-05-1178

[18] Liu, L., et al. (2012) Interleukin-17 and Prostaglandin E2 Are Involved in Formation of an M2 Macrophage-Dominant Microenvironment in Lung Cancer. Journal of Thoracic Oncology, 7, 1091-1100. https://doi.org/10.1097/JTO.0b013e3182542752

[19] Heusinkveld, M., et al. (2011) M2 Macrophages Induced by Prostaglandin E2 and IL-6 from Cervical Carcinoma Are Switched to Activated M1 Macrophages by 
CD4+ Th1 Cells. The Journal of Immunology, 187, 1157-1165.

https://doi.org/10.4049/jimmunol.1100889

[20] Baratelli, F., et al. (2005) Prostaglandin E2 Induces FOXP3 Gene Expression and T Regulatory Cell Function in Human CD4+ T Cells. The Journal of Immunology, 175, 1483-1490. https://doi.org/10.4049/jimmunol.175.3.1483

[21] Sinha, P., Clements, V.K., Fulton, A.M. and Ostrand-Rosenberg, S. (2007) Prostaglandin E2 Promotes Tumor Progression by Inducing Myeloid-Derived Suppressor Cells. Cancer Research, 67, 4507-4513. https://doi.org/10.1158/0008-5472.CAN-06-4174

[22] Wasserman, J., et al. (1989) Immunosuppression in Irradiated Breast Cancer Patients: In Vitro Effect of Cyclooxygenase Inhibitors. The bulletin of the New York Academy of Medicine, 65, 36-44.

[23] Motz, G.T., et al. (2014) Tumor Endothelium FasL Establishes a Selective Immune Barrier Promoting Tolerance in Tumors. Nature Medicine, 20, 607-615. https://doi.org/10.1038/nm.3541

[24] Esquivias, P., et al. (2012) Indomethacin but Not a Selective Cyclooxygenase-2 Inhibitor Inhibits Esophageal Adenocarcinogenesis in Rats. World Journal of Gastroenterology, 18, 4866-4874. https://doi.org/10.3748/wjg.v18.i35.4866

[25] Cho, M., et al. (2013) Aspirin Blocks EGF-Stimulated Cell Viability in a COX-1 Dependent Manner in Ovarian Cancer Cells. Journal of Cancer, 4, 671-678. https://doi.org/10.7150/jca.7118

[26] Kim, M.S., et al. (2014) Naproxen Induces Cell-Cycle Arrest and Apoptosis in Human Urinary Bladder Cancer Cell Lines and Chemically Induced Cancers by Targeting PI3K. Cancer Prevention Research, 7, 236-245. https://doi.org/10.1158/1940-6207.CAPR-13-0288

[27] Brunelli, C., Amici, C., Angelini, M., Fracassi, C., Belardo, G. and Santoro, M.G. (2012) The Non-Steroidal Anti-Inflammatory Drug Indomethacin Activates the eIF2alpha Kinase PKR, Causing a Translational Block in Human Colorectal Cancer Cells. Biochemical Journal, 443, 379-386. https://doi.org/10.1042/BJ20111236

[28] Gabri, M.R., et al. (2006) Complete Antitumor Protection by Perioperative Immunization with GM3/VSSP Vaccine in a Preclinical Mouse Melanoma Model. Clinical Cancer Research, 12, 7092-7098. https://doi.org/10.1158/1078-0432.CCR-06-1075

[29] Carr, A., et al. (2003) Immunotherapy of Advanced Breast Cancer with a Heterophilic Ganglioside (NeuGcGM3) Cancer Vaccine. Journal of Clinical Oncology, 21, 1015-1021. https://doi.org/10.1200/JCO.2003.02.124

[30] Ramirez, B.S., et al. (2006) Active Antimetastatic Immunotherapy in Lewis Lung Carcinoma with Self EGFR Extracellular Domain Protein in VSSP Adjuvant. International Journal of Cancer, 119, 2190-2199. https://doi.org/10.1002/ijc.22085

[31] Torrens, I., et al. (2005) Immunotherapy with CTL Peptide and VSSP Eradicated Established Human Papillomavirus (HPV) Type 16 E7-Expressing Tumors. Vaccine, 23, 5768-5774. https://doi.org/10.1016/j.vaccine.2005.07.049

[32] Mesa, C., de Leon, J. and Fernandez, L.E. (2006) Very Small Size Proteoliposomes Derived from Neisseria meningitidis: An Effective Adjuvant for Generation of CTL Responses to Peptide and Protein Antigens. Vaccine, 24, 2692-2699. https://doi.org/10.1016/j.vaccine.2005.08.111

[33] Mesa, C., de León, J., Rigley, K. and Fernández, L.E. (2004) Very Small Size Proteoliposomes Derived from Neisseria meningitidis. An Effective Adjuvant for Th1 Induction and Dendritic Cell Activation. Vaccine, 22, 3045-3052. https://doi.org/10.1016/j.vaccine.2004.02.010 
[34] Oliver, L., Fernández, A., Raymond, J., López-Requena, A., Fernández, L.E. and Mesa, C. (2012) Very Small Size Proteoliposomes Derived from Neisseria meningitidis: An Effective Adjuvant for Antigen-Specific Cytotoxic T Lymphocyte Response Stimulation under Leukopenic Conditions. Vaccine, 30, 2963-2972. https://doi.org/10.1016/j.vaccine.2012.02.054

[35] Fernandez, A., et al. (2011) Inhibition of Tumor-Induced Myeloid-Derived Suppressor Cell Function by a Nanoparticulated Adjuvant. The Journal of Immunology, 186, 264-274. https://doi.org/10.4049/jimmunol.1001465

[36] Lutz, M.B., et al. (1999) An Advanced Culture Method for Generating Large Quantities of Highly Pure Dendritic Cells from Mouse Bone Marrow. Journal of Immunological Methods, 223, 77-92. https://doi.org/10.1016/S0022-1759(98)00204-X

[37] Brasel, K., et al. (2000) Generation of Murine Dendritic Cells from Flt3-LigandSupplemented Bone Marrow Cultures. Blood, 96, 3029-3039.

[38] Estevez, F., et al. (1999) Enhancement of the Immune Response to Poorly Immunogenic Gangliosides after Incorporation into Very Small Size Proteoliposomes (VSSP). Vaccine, 18, 190-197. https://doi.org/10.1016/S0264-410X(99)00219-4

[39] Labrada, M., et al. (2010) Direct Validation of NGcGM3 Ganglioside as a New Target for Cancer Immunotherapy. Expert Opinion on Biological Therapy, 10, 153 162. https://doi.org/10.1517/14712590903443084

[40] Verdijk, R.M., et al., (1999) Polyriboinosinic Polyribocytidylic Acid (Poly(I:C)) Induces Stable Maturation of Functionally Active Human Dendritic Cells. The Journal of Immunology, 163, 57-61.

[41] Whiteside, T.L. (2010) Inhibiting the Inhibitors: Evaluating Agents Targeting Cancer Immunosuppression. Expert Opinion on Biological Therapy, 10, 1019-1035. https://doi.org/10.1517/14712598.2010.482207

[42] Harizi, H., Juzan, M., Pitard, V., Moreau, J.-F. and Gualde, N. (2002) Cyclooxygenase-2-Issued Prostaglandin e(2) Enhances the Production of Endogenous IL-10, Which Down-Regulates Dendritic Cell Functions. The Journal of Immunology, 168, 2255-2263. https://doi.org/10.4049/jimmunol.168.5.2255

[43] Baratelli, F., et al. (2010) PGE (2) Contributes to TGF-Beta Induced T Regulatory Cell Function in Human Non-Small Cell Lung Cancer. American Journal of Translational Research, 2, 356-367.

[44] Yamaki, K., et al. (2003) Effect of the Nonsteroidal Anti-Inflammatory Drug Indomethacin on Th1 and Th2 Immune Responses in Mice. Journal of Pharmaceutical Sciences, 92, 1723-1729. https://doi.org/10.1002/jps.10380

[45] Hadrup, S., Donia, M. and Straten, P.T. (2013) Effector CD4 and CD8 T Cells and Their Role in the Tumor Microenvironment. Cancer Microenvironment, 6, 123 133. https://doi.org/10.1007/s12307-012-0127-6

[46] Inoue, J. and Aramaki, Y. (2007) Cyclooxygenase-2 Inhibition Promotes Enhancement of Antitumor Responses by Transcutaneous Vaccination with Cytosine-Phosphate-Guanosine-Oligodeoxynucleotides and Model Tumor Antigen. Journal of Investigative Dermatology, 127, 614-621. https://doi.org/10.1038/sj.jid.5700656

[47] Kas'ianenko, I.V., et al. (1992) [The Immunomodulating Role of Indomethacin in the Chemoradiation Treatment of Inoperable Patients with Lung Cancer]. Voprosy onkologii, 38, 1183-1187.

[48] Moroz, T.D., et al. (1989) [Effect of Indomethacin on the Immunological Indices of Patients with Inoperable Stomach Cancer]. Eksp Onkol, 11, 66-68.

[49] Mavligit, G.M., Raphael, L.S., Calvo, D.B. III and Wong, W.L. (1980) Indometha- 
cin-Induced, Monocyte-Dependent Restoration of Local Graft-Versus-Host Reaction among Cells from Cancer Patients. Journal of the National Cancer Institute, 65, 317-320.

[50] Liu, J.Q., et al. (2010) [Mechanistic Study of Nimesulide on Enhancing Gammadeltat Cell-Mediated Killing of Gastric Cancer Cells]. Chinese Journal of Cellular and Molecular Immunology, 26, 261-263.

[51] Kundu, N., Walser, T.C., Ma, X. and Fulton, A.M. (2005) Cyclooxygenase Inhibitors Modulate NK Activities That Control Metastatic Disease. Cancer Immunology, Immunotherapy, 54, 981-987. https://doi.org/10.1007/s00262-005-0669-2

[52] Lee, S.Y., et al. (2009) The Immune Tolerance of Cancer Is Mediated by IDO That Is Inhibited by COX-2 Inhibitors through Regulatory T Cells. Journal of Immunotherapy, 32, 22-28. https://doi.org/10.1097/CJI.0b013e31818ac2f7

[53] Morecki, S., Yacovlev, E., Gelfand, Y., Trembovler, V., Shohami, E. and Slavin, S. (2000) Induction of Antitumor Immunity by Indomethacin. Cancer Immunology, Immunotherapy, 48, 613-620. https://doi.org/10.1007/s002620050009

[54] Stolina, M., et al. (2000) Specific Inhibition of Cyclooxygenase 2 Restores Antitumor Reactivity by Altering the Balance of IL-10 and IL-12 Synthesis. The Journal of Immunology, 164, 361-370. https://doi.org/10.4049/jimmunol.164.1.361

[55] Park, W., Oh, Y.T., Han, J.H. and Pyo, H. (2008) Antitumor Enhancement of Celecoxib, a Selective Cyclooxygenase-2 Inhibitor, in a Lewis Lung Carcinoma Expressing Cyclooxygenase-2. Journal of Experimental \& Clinical Cancer Research, 27, 66. https://doi.org/10.1186/1756-9966-27-66

[56] Pozzi, A., et al. (2004) Colon Carcinoma Cell Growth Is Associated with Prostaglandin E2/EP4 Receptor-Evoked ERK Activation. The Journal of Biological Chemistry, 279, 29797-29804. https://doi.org/10.1074/jbc.M313989200

[57] Connolly, E.M., et al. (2002) Cyclo-Oxygenase Inhibition Reduces Tumour Growth and Metastasis in an Orthotopic Model of Breast Cancer. British Journal of Cancer, 87, 231-237. https://doi.org/10.1038/sj.bjc.6600462

[58] Favalli, C., et al. (1980) Influence of PGE on the Immune Response in Melanoma-Bearing Mice. The Journal of Immunology, 125, 897-902.

\section{Submit or recommend next manuscript to SCIRP and we will provide best} service for you:

Accepting pre-submission inquiries through Email, Facebook, LinkedIn, Twitter, etc. A wide selection of journals (inclusive of 9 subjects, more than 200 journals)

Providing 24-hour high-quality service

User-friendly online submission system

Fair and swift peer-review system

Efficient typesetting and proofreading procedure

Display of the result of downloads and visits, as well as the number of cited articles

Maximum dissemination of your research work

Submit your manuscript at: http://papersubmission.scirp.org/

Or contact jet@scirp.org 